\title{
TERAPI REFLEKSI AL-FATIHAH (AL-FATIHAH REFLECTION THERAPY)
}

\author{
Saktiyono B. Purwoko \\ Employee Assistance PT. Liebra Permana \\ E-mail: saktiyono@ymail.com
}

\begin{abstract}
Al Fatihah reflection Therapy (ART) is a theistic psychotherapy that shares characteristics with Cognitive Behavior Therapy (CBT) from Beck. However, the conceptualization and intervention emphasis differs in some ways. The ART has a vertical dimension (theistic) which uses the verses of Al Fatiha as a reflection of the changing thoughts, feelings, and behavior of individuals through restructuring cognitive, reading passages, and behavioral tasks. It is expected the ART can be applied, do research, and can be considered as a single intervention or additional interventions for Muslim clients.
\end{abstract}

Keywords : Al-Fatihah, Reflection, Cognitive Restructuring, Verses Recitation, Behavioral Task.

\begin{abstract}
Abstrak
Al Fatihah Refelction Therapy (ART) adalah psikoterapi teistik yang berbagi karakteristik dengan Cognitive Behavior Therapy (CBT) dari Beck. Namun konseptualisasi dan penekanan intervensinya berbeda dalam beberapa segi. ART memiliki dimensi vertikal (teistik) yang menggunakan ayat-ayat Al Fatihah sebagai refleksi dalam mengubah pikiran, perasaan, dan perilaku disfunsgional individu melalui restrukturisasi kognitif, pembacaan ayat-ayat, dan tugas perilaku. Harapannya, ART dapat diterapkan, dilakukan penelitian, dan bisa dipertimbangkan sebagai intervensi tunggal atau intervensi tambahan bagi klien muslim.
\end{abstract}

Kata kunci : Al-Fatihah, Refleksi, Restrukturisasi Kognitif, Pembacaan Ayat, Tugas Perilaku.

$\mathrm{B}$ aru-baru ini muncul kecenderungan di antara para psikolog yang menyerukan pentingnya agama dalam mengatasi gangguan psikologis (Ancok \& Suroso, 2008; Najati, 2010). Hal tersebut didasari pada asumsi bahwa "Tuhan itu ada dan manusia merupakan ciptaan Tuhan" (Richards \& Bergin, 2006). Manusia memang merupakan materi yang diciptakan Tuhan untuk beribadah kepada-Nya, yang diberi potensi kehidupan (fitrah) dan potensi akal, serta dalam area yang dikuasainya diberikan kebebasan dalam menentukan atau memilih perilakunya melalui fungsi qalbunya (Purwoko, 2012). Kurangnya pengenalan terhadap Tuhan sebagai "The ultimate source" yang memberikan petunjuk, keringanan, perlindungan, dukungan, dan keberlangsungan hidup, dapat membuat manusia rentan mengalami kecemasan, depresi, dan gangguan psikologis lainnya (Elkadi, 
1985).

Kebanyakan klien memandang kekuatan religius mereka sebagai aset vital dalam menghadapi permasalahannya (Hamdan, 2008). Bahkan, Corey (2009) yang karya tulisnya menjadi rujukan utama di berbagai Fakultas/Program Studi Psikologi di Indonesia, telah mengintegrasikan nilai religius dalam buku teori dan praktik konselingnya.

P. Scott Richards dan Allen E. Bergin (2006) dari American Psychological Association (APA) menawarkan sebuah strategi psikoterapi yang bernama psikoterapi teistik, yaitu pendekatan psikoterapi yang didasari pandangan teistik, yang juga menyerap dan mengintegrasikan psikoterapi utama, seperti psikodinamik, interpersonal, perilaku, kognitif, dan humanistik.

Berbagai upaya sudah dilakukan psikoterapis untuk mengadaptasi intervensi kognitif-perilaku dengan pandangan teistik dari agama Islam, Kristen, Yahudi, Taoisme, dan Buddha. Integrasi tersebut sudah dipraktikkan, dilakukan penelitiannya, dan dipublikasikan (Razali dkk, 1998; Hamdan, 2008; Waller dkk, 2010). Upaya yang dilakukan adalah mengganti pikiran dan keyakinan disfungsional mengenai diri, orang lain dan dunia dengan pikiran dan keyakinan yang lebih fungsional dari pandangan atau keyakinan agama (Hamdan, 2008). Sebagai contoh, konsepsi-konsepsi yang diambil dari pandangan Buddhisme telah memengaruhi perkembangan intervensi kognitif-perilaku yang baru, yaitu Dialectical Behaviour Therapy, Mindfulness-Based Cognitive Therapy, dan Compassion Focused Therapy (Waller dkk, 2010). Ayat-ayat dalam kitab suci telah digunakan psikoterapis kognitif-perilaku untuk membantu klien mengubah pikiran dan keyakinan disfungsionalnya. Metode ini dapat dikategorikan dalam intervensi religius (Richards \& Bergin, 2006).

Malik B. Badri (1996) dan Aisha Hamdan (2008) adalah contoh psikoterapis muslim yang menggunakan ayat-ayat al-Qur'an beserta hadits untuk mengubah pikiran dan keyakinan disfungsional kliennya melalui pendekatan intervensi kognitif. Menurut Hamdan (2008), hal tersebut dapat dilakukan dengan cara mengikuti model restrukturisasi kognitif. Mula-mula pikiran otomatis, core beliefs, dan asumsiasumsi disfungsional klien diidentifikasi. Proses selanjutnya adalah mengevaluasi dan memodifikasi pikiran otomatisnya, kemudian mengevaluasi dan memodifikasi asumsi-asumsi dan core beliefs-nya.

Pada proses restrukturisasi kognitif tersebut, pandangan Islam (cognitions from the Islamic faith) didiskusikan, yang kemudian ditawarkan sebagai penjelasan alternatif atau melawan (to counter) pikiran dan keyakinan disfungsionalnya. Adapun pandangan Islam spesifik yang dipilih bergantung pada permasalahan klien(Hamdan, 2008).

\section{TADABBUR AL-QUR'AN}

Berdasarkan perspektif agama Islam, tadabbur ayat-ayat al-Qur'an dapat dijadikan upaya untuk mengatasi gangguan psikologis. Hal tersebut termuat dalam surat al-Qur'an berikut ini:

"Hai manusia, sesungguhnya telah datang kepadamu pelajaran dari Tuhanmu dan penyembuh bagi penyakit-penyakit (yang berada) dalam dada dan petunjuk serta rahmat bagi orang-orang yang beriman" (QS. Yunus : 57).

Khalid Abdul Karim al-Lahim (2006), salah satu guru besar al-Qur'an dan Ulumul Quran, menyatakan bahwa tadabbur al-Qur'an adalah upaya 
memikirkan dan merenungi ayat-ayat alQur'an agar dapat memahaminya dan mengungkap makna, hikmah, serta maksud yang dikehendakinya. Dengan men-tadabbur al-Qur'an, maka individu dapat mengambil pelajaran, dan perasaannya menjadi tenteram. Hal tersebut termuat dalam surat al-Qur'an berikut ini:

"Ini adalah sebuah kitab penuh berkah yang Kami turunkan kepadamu supaya mereka memperhatikan ayat-ayatnya dan agar orang-orang yang mempunyai pikiran mendapat pelajaran" (QS. Shâd: 29).

"Allah telah menurunkan perkataan yang paling baik (yaitu) al-Qur'an yang serupa (mutu ayat-ayatnya) lagi berulang-ulang, gemetar karenanya kulit orang-orang yang takut kepada Tuhannya, kemudian menjadi tenteram kulit dan qalbu mereka di waktu mengingat Allah. Itulah petunjuk Allah, dengan kitab itu Dia menunjuki siapa yang dikehendaki-Nya. Dan barangsiapa yang disesatkan Allah, niscaya tak ada baginya seorang pemimpin pun" (QS. Az-Zumar:23).

Menurut corpus.quran.com dan quran.com, kata tadabbur diterjemahkan dalam bahasa Inggris sebagai reflect. "(This is) a blessed Book which We have revealed to you, (OMuhammad), that they might reflect upon its verses and that those of understanding would be reminded" (QS. Shâd: 29).

Menurut oxforddictionaries.com, refleksi memiliki arti: serious thought or consideration, a thing that is a consequence of or arises from something else, an idea about something especially one that is written down or expressed. Menurut dictionary.com, refleksi memiliki arti: careful consideration, a fixing of the thoughts on something, a thought occurring in consideration or meditation. Sedangkan menurut thefreedictionary.com, refleksi memiliki arti: a thought or an opinion resulting from such consideration, an indirect expression of censure or discredit, a manifestation or result. Dari pengertian-pengertian refleksi tersebut, dapat disimpulkan bahwa refleksi mengandung makna keseriusan dalam berpikir, pemikiran yang muncul dari suatu pertimbangan, perbaikan pemikiran pada sesuatu, dan manifestasi (pikiran, perasaan, perilaku) dari sesuatu.

Dengan demikian, bagi individu yang mengalami gangguan psikologis yang ditimbulkan oleh pikiran dan keyakinan disfungsional, maka tadabbur al-Qur'an dapat dijadikan upaya untuk mengatasinya. Yaitu, dengan merefleksikan ayat-ayat al-Qur'an, agar individu serius memikirkan ayat-ayatnya, memperbaiki pikirannya, mendapatkan pembelajaran ulang yang adaptif atas pengalaman-pengalamannya, dan perasaannya menjadi tenteram.

\section{REFLEKSI AYAT-AYAT AL- FATIHAH}

Di dalam kitab suci al-Qur'an terdapat surat pendek yang merupakan induk dari al-Qur'an, yang seringkali dibaca setiap hari dan hampir setiap muslim mengetahui artinya. Surat tersebut adalah al-Fatihah. Abu Hurairah r.a. berkata, Nabi saw bersabda: "Surat 'Alhamdulillâhi rabbil 'âlamîn (alFatihah) ialah Ummul Quran, juga Ummul Kitab, dan Assab'ul Matsani dan al-Qur'anul Adzim" (HR. at-Tirmidzi).

Bukhari (Bahreisy \& Bahreisy, 1993) berkata bahwa surat Al-Fatihah dinamakan Ummul Quran (induk dari alQur'an), karena ia mengandung semua isi al-Qur'an. Ummul Kitab (induk dari semua kitab Allah) yang telah diturunkan kepada nabi-nabi-Nya, seakan-akan isi dari semua apa yang diwahyukan Allah kepada nabinabi disimpulkan dalam al-Fatihah. Assab'ul Matsani (tujuh ayat pujian yang selalu diulang-ulang) oleh setiap muslim 
sekurang-kurangnya 17 kali dalam sehari semalam, dalam salat fardu. Al-Qur'anul Adzim karena surat yang terbesar dalam alQur'an.

Nama-nama surat al-Fatihah antara lain al-Asâs (asas segala sesuatu), al-Kanz (perbendaharaan), asy-Syâfiyah (penyembuh), al-Kâfiyah (yang mencukupi), al-Wâqiyah (yang melindungi), ar-Ruqyah (mantera), alHamd (pujian), asy-Syukr (syukur), adDu'â dan ash-Shalât (Shihab, 2004). Dari nama asy-Syâfiyah dan ar-Ruqyah, maka dapat dikatakan bahwa surat al-Fatihah memiliki potensi terapeutik.

Di antara para ulama yang berpendapat bahwa surat al-Fatihah dapat digunakan untuk mengatasi gangguan psikologis adalah Ibnu Qayyim al-Jauziah (Arifin, 1976) di bukunya yang bernama "Madarijus Salikin" dan M. Quraish Shihab (2004) di bukunya yang bernama "Tafsir Al-Mishbah". Menurut al-Jauziah
(Arifin, 1976), surat al-Fatihah mengandung penawar buat qalbu. Cacatcacat atau penyakit yang menimpa qalbu berpokok pada dua perkara, yaitu rusaknya ilmu dan rusaknya tujuan. Adapun menurut Shihab (2004), surat alFatihah itu dapat mencukupi manusia dalam mengatasi segala keresahan, melindunginya dari segala keburukan, dan menjadi mantera dalam menghadapi segala kesulitan.

Berdasarkan penafsiran surat alFatihah dari berbagai sumber tafsir alQur'an (Arifin, 1976; Bahreisy \& Bahreisy, 1993; Rasyidi, Sitanggal, Aly \& Abubakar, 1992; Shihab, 2004) yang berkaitan dengan proses mental dan proses perilaku (Atkinson \& Hilgard's, 2003), maka penulis menemukan bagaimana kandungan ayat-ayat al-Fatihah dapat merefleksikan pikiran, perasaan, hingga perilaku individu (muslim). 
Tabel 1. Refleksi ayat-ayat al-Fatihah terhadap pikiran, perasaan, dan perilaku individu

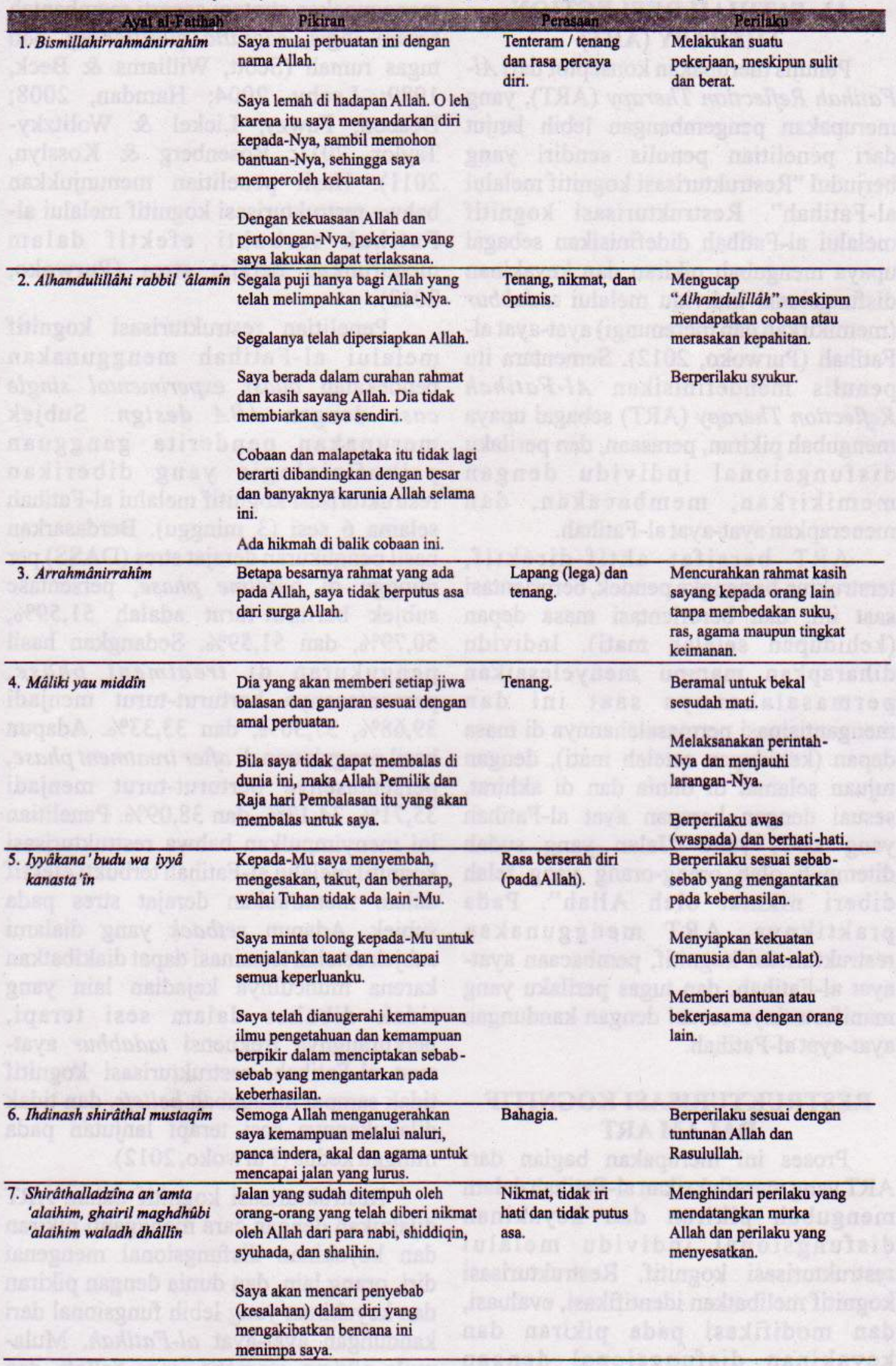




\section{AL-FATIHAH REFLECTION THERAPY (ART)}

Penulis merupakan konseptor dari $\mathrm{Al}$ Fatihah Reflection Therapy (ART), yang merupakan pengembangan lebih lanjut dari penelitian penulis sendiri yang berjudul "Restrukturisasi kognitif melalui al-Fatihah". Restrukturisasi kognitif melalui al-Fatihah didefinisikan sebagai upaya mengubah pikiran dan keyakinan disfungsional individu melalui tadabbur (memikirkan dan merenungi) ayat-ayat alFatihah (Purwoko, 2012). Sementara itu penulis mendefinisikan Al-Fatihah Reflection Therapy (ART) sebagai upaya mengubah pikiran, perasaan, dan perilaku disfungsional individu dengan memikirkan, membacakan, dan menerapkan ayat-ayat al-Fatihah.

ART bersifat aktif-direktif, terstruktur, berjangka pendek, berorientasi saat ini, dan berorientasi masa depan (kehidupan setelah mati). Individu diharapkan mampu menyelesaikan permasalahannya saat ini dan mengantisipasi permasalahannya di masa depan (kehidupan setelah mati), dengan tujuan selamat di dunia dan di akhirat, sesuai dengan harapan ayat al-Fatihah yang ke-7, yaitu "Jalan yang sudah ditempuh oleh orang-orang yang telah diberi nikmat oleh Allah". Pada praktiknya, ART menggunakan restrukturisasi kognitif, pembacaan ayatayat al-Fatihah, dan tugas perilaku yang manifestasinya sesuai dengan kandungan ayat-ayat al-Fatihah.

\section{RESTRUKTURISASI KOGNITIF DALAM ART}

Proses ini merupakan bagian dari ART yang merefleksikan al-Fatihah dalam mengubah pikiran dan keyakinan disfungsional individu melalui restrukturisasi kognitif. Restrukturisasi kognitif melibatkan identifikasi, evaluasi, dan modifikasi pada pikiran dan keyakinan disfungsional dengan menggunakan strategi seperti membantah secara logis, socratic questioning, dan tugas rumah (Scott, Williams \& Beck, 1989; Leahy, 2004; Hamdan, 2008; Deacon, Fawzy, Lickel \& WolitzkyTaylor, 2011; Rosenberg \& Kosslyn, 2011). Hasil penelitian menunjukkan bahwa restrukturisasi kognitif melalui alFatihah terbukti efektif dalam menurunkan derajat stres (Purwoko, 2012).

Penelitian restrukturisasi kognitif melalui al-Fatihah menggunakan pendekatan quasi experimental single case dengan $A B A$ design. Subjek merupakan penderita gangguan psikofisiologis yang diberikan restrukturisasi kognitif melalui al-Fatihah selama 6 sesi (3 minggu). Berdasarkan hasil pengukuran derajat stres (DASS) per minggu di baseline phase, persentase subjek berturut-turut adalah $51,59 \%$, $50,79 \%$, dan $51,59 \%$. Sedangkan hasil pengukuran di treatment phase, persentasenya berturut-turut menjadi $39,68 \%, 37,30 \%$, dan 33,33\%. Adapun hasil pengukuran di after treatment phase, persentasenya berturut-turut menjadi $35,71 \%, 34,13 \%$, dan $38,09 \%$. Penelitian ini menyimpulkan bahwa restrukturisasi kognitif melalui al-Fatihah terbukti efektif dalam menurunkan derajat stres pada subjek. Adapun setback yang dialami subjek setelah terminasi dapat diakibatkan karena munculnya kejadian lain yang tidak dibahas dalam sesi terapi, berkurangnya frekuensi tadabbur ayatayat al-Fatihah, restrukturisasi kognitif tidak sampai mengubah beliefs, dan tidak dilakukannya sesi terapi lanjutan pada minggu kedua (Purwoko, 2012).

Restrukturisasi kognitif dalam ART dilakukan dengan cara mengganti pikiran dan keyakinan disfungsional mengenai diri, orang lain, dan dunia dengan pikiran dan keyakinan yang lebih fungsional dari kandungan ayat-ayat al-Fatihah. Mulamula pikiran otomatis, core beliefs, dan 
asumsi-asumsi disfungsional individu diidentifikasi. Proses selanjutnya adalah mengevaluasi dan memodifikasi pikiran otomatisnya, kemudian mengevaluasi dan memodifikasi asumsi-asumsi dan core beliefs-nya.

Dengan demikian, dalam proses restrukturisasi kognitifnya, kandungan ayat-ayat al-Fatihah yang diperoleh dari buku tafsir al-Qur'an surat al-Fatihah didiskusikan, yang kemudian ditawarkan sebagai penjelasan alternatif atau melawan pikiran dan keyakinan disfungsionalnya. Adapun ayat al-Fatihah yang akan dipilih bergantung pada permasalahan individu. Pada dasarnya, tafsir al-Qur'an manapun dapat digunakan dalam diskusi tersebut, selama tafsir alQur'an tersebut memenuhi kaidah-kaidah penafsiran al-Qur'an.

Upaya diskusi tersebut dapat dimulai dengan gaya Socratic Questions, yang bertujuan untuk mengubah pikiran (Padesky, 1993). Pertanyaan standar untuk mengidentifikasi pikiran dan keyakinan disfungsional individu dalam ART adalah "Bila melihat ayat 7, dapatkah anda temukan pikiran / keyakinan yang mengakibatkan emosi negatif ini menimpa anda?" Teknik-teknik mengidentifikasi pikiran dan keyakinan disfungsional seperti Downward Arrow Technique, serta lembar kerja Cognitive Conceptualization Diagram dari Beck (1995) dapat digunakan dalam proses ini.

Setelah pikiran dan keyakinan disfungsionalnya diidentifikasi, maka individu diperlihatkan bacaan tafsir alQur'an surat al-Fatihah, kemudian diajak berdiskusi untuk mengevaluasi pikiran disfungsionalnya dengan membuka pertanyaan standar: "Menurut anda, kandungan ayat al-Fatihah mana yang membuat anda merasa lebih nyaman ketika menghadapi situasi ini?".

Di proses awal ini, individu dibebaskan untuk memilih kandungan ayat al-Fatihah mana saja yang dapat membuat perasaannya lebih nyaman. Bila individu mengalami kesulitan dalam memilih kandungan ayat al-Fatihah, terapis dapat membimbing individu untuk melihat kandungan ayat al-Fatihah tertentu yang dianggap terapis mampu mengatasi pikiran disfungsional individu.

Berikut ini adalah pertanyaanpertanyaan standar dalam ART yang penulis susun sendiri, yaitu ketika terapis membimbing individu mengevaluasi pikiran disfungsionalnya. Salah satu diantaranya berasal dari Beck(1995).

Tabel 2. Mengevaluasi pikiran disfungsional

\section{Mengevaluasi Pikiran Disfungsional}

1. Apa bukti yang mendukung pikiran anda? Apa bukti yang bertentangan dengan pikiran anda? (Beck, 1995)

2. Apa efeknya bila anda mengubah pikiran dengan melihat ayat $1,2,3,4,5,6$ atau 7 ?

3. Bila melihat ayat 2 , hikmah atau pelajaran apa yang mungkin dapat anda peroleh dari situasi ini? Apa yang masih dapat anda syukuri dalam situasi ini Dapatkah anda temukan (kekuatan) apa saja yang disediakan Allah untuk anda dalam menghadapi situasi ini? Apa yang masih dapat anda lakukan untuk bersyukur pada Nya?

4. Bila melihat ayat 5, apa permintaan spesifik anda pada Allah dalam situasi ini? Apa yang dapat anda lakukan untuk mewujudkannya? Siapa orang yang mungkin dapat anda mintai tolong?

5. Bila melihat ayat 6 , pikiran atau perilaku apa yang ingin anda ubah agar sesuai dengan tuntunan Allah dan Rasulullah? 
berkurang pada tujuh kelompok, di mana level penurunan yang paling signifikan terjadi pada partisipan yang mendengarkan ayat-ayat al-Qur'an.

Majidi (2004) menyatakan bahwa pembacaan al-Qur'an mengurangi derajat kecemasan dan tanda-tanda vital, sehingga menjadikan prosedur yang aman dan murah dalam mengurangi kecemasan sebelum dilakukan pembedahan. Majidi (2004) melakukan penelitian terhadap 108 pasien yang akan menjalankan coronary artery angiography. Sebanyak 54 pasien dipilih secara acak ke dalam kelompok kontrol dan 54 lainnya ke dalam kelompok eksperimental. Bacaan al-Qur'an didengarkan pada kelompok eksperimental selama 20 menit. Hasilnya, derajat state and trait anxiety pada kelompok eksperimental berkurang secara signifikan dibandingkan kelompok kontrol. Derajat tanda-tanda vital pada kelompok eksperimental juga berkurang secara signifikan dibandingkan kelompok kontrol.

Penelitian-penelitian tersebut senada dengan pernyataan Elkadi (1985), bahwasanya perubahan efek melalui bacaan al-Qur'an dapat diperoleh melalui dua mekanisme. Pertama, melalui suara yang dihasilkan saat membaca al-Qur'an. Kedua, melalui pemaknaan bacaan alQur'an yang dapat dimengerti oleh individu.

Berkenaan dengan mekanisme pertama, tersirat bahwa bacaan al-Qur'an mampu mengubah perasaan disfungsional individu tanpa melalui proses kognitif (pemaknaan) terlebih dahulu. Penelitian yang dilakukan oleh Carrie M. York (2011) menunjukkan bahwa kedua partisipan non-muslim yang mengalami perasaan disfungsional, setelah dibacakan al-Qur'an oleh syaikh selama kurang lebih 12 menit, dapat merasakan respon fisik yang kuat dan merasakan kemajuan positif atas keluhan-keluhannya saat ini. Pada mekanisme pertama ini, belum diketahui secara jelas bagaimana proses mentalnya, masih perlu penelaahan dan penelitian lebih lanjut.

Adapun dengan mekanisme kedua, sejalan dengan model kognitif dari Beck (1995) yang menyatakan bahwa pikiran memengaruhi perasaan individu. Mekanisme kedua ini dapat dilakukan manakala sejumlah pikiran dan keyakinan yang lebih fungsional pada individu telah ditemukan. Setelah itu, individu diminta untuk membaca ayat-ayat al-Fatihah, baik ketika shalat ataupun membacanya secara terpisah, dengan merenungi makna, hikmah, serta maksud yang dikehendaki surat al-Fatihah (pikiran dan keyakinan yang lebih fungsional yang digali saat sesi terapi).

Surat al-Fatihah memiliki keunikan saat dibaca dibandingkan surat al-Qur'an yang lain. Karena setiap ayat al-Fatihah yang dibaca, langsung dijawab oleh Allah (Arifin, 1976).

Abu Hurairah r.a. berkata, bahwa Nabi saw bersabda: "Allah Azza wa Jalla berfirman, 'Aku telah membagi shalat itu menjadi dua bagian, antara-Ku dengan hamba-Ku, dan terserah-Ku apa yang ia m i t a . M a k j i k a membaca,'Alhamdulillâhi rabbil 'âlamîn'. Jawab Allah, 'Hamba-Ku telah memuji$\mathrm{Ku}^{\prime}$ (Hamba-Ku bersyukur pada-Ku). Dan bila membaca, 'Arrahmânirrahîm'. Jawab Allah, 'Hamba-Ku telah menyanjung-Ku'. Dan bila membaca, 'Mâliki yau middîn'. Jawab Allah, 'Hamba-Ku telah memuliakan Aku' (Hamba-Ku menyerahkan urusannya kepada-Ku). Maka jika membaca, 'Iyyâkana' budu wa iyyâ kanasta'în'. Jawab Allah, 'Ini yang di antara-Ku dengan hamba-Ku dan terserah pada hamba-Ku apa yang ia minta'. Jika membaca, 'Ihdinash shirâthal mustaqîm, shirâthalladzîna an'amta 'alaihim, ghairil maghdhûbi 'alaihim waladh dhâlîn'. Jawab Allah, 'Itu semua Aku beri pada 
Tidak semua pertanyaan tersebut diberikan, karena akan menyita banyak waktu, gunakan beberapa pertanyaan yang paling dianggap berkaitan dengan permasalahan spesifik individu. Adapun pertanyaan-pertanyaan standar untuk mengevaluasi keyakinan disfungsional individu serupa dengan mengevaluasi pikiran disfungsionalnya, misalnya: "Apa efeknya bila anda mengubah keyakinan dengan melihat ayat 1, 2, 3, 4, 5, 6 atau 7 ?", atau "Bila melihat ayat 6 , keyakinan apa yang ingin anda ubah agar sesuai dengan tuntunan Allah dan Rasulullah ?".

Individu yang memiliki core beliefs "Saya tidak kompeten" dapat mendiskusikan surat al-Fatihah ayat 1 , yaitu "Saya lemah di hadapan Allah, oleh karena itu saya menyandarkan diri kepada-Nya, sambil memohon bantuanNya, sehingga saya memperoleh kekuatan", atau mendiskusikan surat alFatihah ayat 5, yaitu "Saya minta tolong kepada-Mu untuk menjalankan taat dan mencapai semua keperluanku". Sedangkan individu yang memiliki core beliefs "Saya tidak dicintai" dapat mendiskusikan surat al-Fatihah ayat 2 , yaitu "Saya berada dalam curahan rahmat dan kasih sayang Allah. Dia tidak membiarkan saya sendiri", atau mendiskusikan surat al-Fatihah ayat 3, yaitu " $A r$-Rahmân yang memberi nikmat yang sebesar-besarnya. Ar-Rahîm yang memberi nikmat halus sehingga tidak terasa."

Pikiran dan keyakinan yang ditawarkan sebagai penjelasan alternatif atau melawan pikiran dan keyakinan disfungsionalnya tersebut berkaitan dengan topik yang dibahas dan selaras dengan kandungan tafsir al-Qur'an surat al-Fatihah, terutama ayat 6 dan 7. Arifin (1976) menyatakan bahwa "Shirâthal mustaqîm" memiliki arti jalan yang lurus, jalan yang benar, jalan yang membawa pada kebahagiaan di dunia dan di akhirat. Sedangkan Ibnu Katsier (Bahreisy \&
Bahreisy, 1993) menyatakan bahwa "Shirâthal mustaqîm" ialah mengikuti tuntunan Allah dan Rasulullah saw. Yaitu, jalan yang dahulu sudah ditempuh oleh orang-orang yang mendapat ridha dan nikmat dari Allah, seperti para nabi, shiddiqin, syuhada, dan shalihin.

Hasil diskusi tersebut diharapkan mampu menghasilkan sejumlah pikiran dan keyakinan yang lebih fungsional pada individu. Dengan demikian dapat mengurangi penilaian individu terhadap situasi yang sebelumnya dianggap mengancam, sehingga reaksinya lebih adaptif.

\section{PEMBACAAN AL-FATIHAH DALAM ART}

Proses ini merupakan bagian dari ART yang merefleksikan al-Fatihah dalam mengubah perasaan disfungsional individu melalui pembacaan ayat-ayat alFatihah. Pembacaan ayat-ayat al-Fatihah yang dimaksud dalam tulisan ini adalah membaca surat al-Fatihah dengan volume suara yang mampu didengar oleh pembacanya dan/atau orang lain yang berada di sekitarnya. Hasil penelitian menunjukkan bahwa membaca al-Qur'an mampu mengurangi perasaan disfungsional, seperti depresi (Rana \& North, 2007) dan kecemasan (Majidi, 2004).

Rana dan North (2007) menyatakan bahwa terdapat efek positif dari pembacaan al-Qur'an yang berirama terhadap pasien muslim yang mengalami depresi psikotik. Rana dan North (2007) melakukan penelitian terhadap 175 pasien depresi psikotik di rumah sakit Pakistan, kemudian membaginya menjadi tujuh kelompok. Setiap kelompok mendapatkan obat dan sesi psikoterapi yang sama, namun 6 kelompok eksperimental ditambahkan 6 jenis perlakuan yang berbeda, selama 60 menit sehari, dalam 30 hari. Hasilnya, level depresi telah 
hamba-Ku dan terserah pada hamba-Ku apa yang akan diminta" (HR. Muslim).

Pada Musnad Ahmad, Sunan Abi Dawud, Shahih Ibn Khuzaimah, dan AlMustadrak yang diriwayatkan dari Ummu Salamah r.a. disebutkan, "Rasulullah saw melakukan jeda pada setiap bacaan bismillahirrahmânirrahîm, alhamdulillâhi rabbil 'âlamîn, arrahmânirrahîm, mâlikiyau middîn".

Abdul Hayy al-Farmawiy (2002), dalam buku "Tafsir Surah al-Fatihah", memberikan gambaran bagaimana membaca surat al-Fatihah ayat per ayat, yaitu: "Berhentilah sejenak dalam membaca surat al-Fatihah pada setiap ayatnya, agar anda mampu menghadirkan makna bacaannya, berusaha memahaminya, dan menanti jawaban Allah dari apa yang telah anda ucapkan itu, seolah-olah anda mendengar-Nya. Tujuannya supaya anda merasakan kenikmatan dekat dengan-Nya, sebagaimana yang terungkap dalam hadits shahih". Misalnya, ketika anda membaca "Alhamdulillâhi rabbil 'âlamîn", maka hadirkanlah maknanya bahwa segala sanjungan yang baik secara haq, adalah milik Allah Ta'ala sebagai suatu keniscayaan maupun kenyataan. Dia adalah Rabb, Pencipta alam semesta, dan Pengatur urusan seluruh makhluk. Tunggu sebentar, seolah-olah anda mendengar Allah mengatakan "Hamba-Ku telah memuji-Ku".

Dengan demikian, di dalam maupun setelah sesi terapi, individu diminta untuk membaca ayat-ayat al-Fatihah dengan cara-cara yang dikemukakan oleh alFarmawiy (2002). Yaitu, berhenti sejenak pada setiap ayatnya, menghayati makna bacaannya (pikiran dan keyakinan yang lebih fungsional yang digali saat sesi terapi), dan menanti jawaban Allah dari apa yang telah diucapkannya itu (sebagaimana yang dikemukakan dalam hadits), seolah-olah individu mendengarNya. Lembar kerja Tadabbur Al-Fatihah dari Purwoko (2012) dapat digunakan dalam proses ini.

Berdasarkan hasil penelitian, kesan subjek saat membaca al-Fatihah sebagaimana prosedur di atas adalah merasa seolah-olah sedang "berdialog langsung" dengan Allah, di antaranya: "Seperti kita sedang ngobrol langsung dengan Tuhan" (Purwoko, 2012). Kesan seperti ini memang bisa didapatkan bilamana ayat yang dibacanya mendapatkan "jawaban langsung" dari Sang Pencipta. Inilah yang menjadi salah satu keunikan ART.

\section{TUGAS PERILAKU DAN CONTOH KASUS}

\section{Tugas Perilaku Dalam Art}

Proses ini merupakan bagian dari ART yang merefleksikan al-Fatihah dalam mengubah perilaku disfungsional individu melalui tugas perilaku. Pada dasarnya, tugas perilaku dalam ART merupakan kelanjutan dari rencana perilaku yang terungkap saat proses restrukturisasi kognitif berlangsung, melalui pertanyaan semisal "Apa yang masih dapat anda lakukan untuk bersyukur pada-Nya? Apa yang dapat anda lakukan untuk mewujudkannya? Perilaku apa yang ingin anda ubah agar sesuai dengan tuntunan Allah dan Rasulullah?" Setelah rencana perilaku terungkap, maka individu berupaya menerapkan rencana perilaku tersebut dalam kehidupan sehari-hari di luar sesi terapi. Lembar kerja Activity Chart dari Beck (1995) dapat digunakan dalam proses ini.

\section{Contoh Kasus Penggunaan ART}

Berikut ini adalah contoh kasus penggunaan ART berdasarkan pengalaman dan pemikiran penulis saat menangani klien.

Terapis: Bila melihat ayat 7 , dapatkah kamu temukan pikiran yang mengakibatkan emosi negatif 
ini menimpa kamu?

Klien : Nilai akhir pelajaran matematika dan bahasa Inggris saya selalu di bawah angka 8 , saya anak yang gagal, belum dapat membahagiakan orangtua.

Terapis :Apa efeknya bila kamu mengubah pikiran dengan melihat ayat 2 ? Apa yang masih dapat kamu syukuri dalam situasi ini?

Klien : Nilai akhir pelajaran lain di atas angka 8 dan saya masih dapat berprestasi di bidang lain, misalnya saya pernah juara pertama karya tulis remaja, juara pertama olahraga lompat jauh sekabupaten.

Terapis :Apakah pikiran alternatif tersebut membuat perasaan kamu lebih nyaman bila diterapkan?

Klien :Ya, ternyata saya tidak sepenuhnya anak yang gagal.

Terapis :Bila melihat ayat 5 , apa permintaan kamu pada Allah dalam situasi ini?

Klien : Semoga di tahun ajaran baru nanti nilai pelajaran matematika dan bahasa Inggris saya dapat mendapat angka 8.

Terapis :Bila melihat ayat 5 lagi, apa yang dapat kamu lakukan untuk mewujudkannya?

Klien :Saya akan ikut salah satu bimbingan belajar ternama di kota saya dan mulai daftar besok.

Terapis :Baiklah, saat ini saya akan mengajarkan kamu bagaimana menghayati ayat-ayat alFatihah, terutama di ayat 2 dan 5 . Nanti, setelah sesi ini berakhir, saya harapkan kamu tetap menghayati ayat-ayat al-Fatihah minimal sekali sehari, dan kamu lakukan pendaftaran bimbingan belajar esok hari. Bagaimana?
Klien : Baiklah, akan saya coba.

\section{KEUNIKAN ART}

ART memiliki berbagai keunikan. Pertama, bacaan surat al-Fatihah relatif pendek dan hampir setiap muslim mengetahui arti/tafsir sederhananya. Kedua, surat al-Fatihah dapat dihayati kapan saja. Ketiga, surat al-Fatihah merupakan induk dari al-Qur'an yang kandungannya dapat ditawarkan sebagai penjelasan alternatif atau melawan pikiran dan keyakinan disfungsional individu, kandungan surat al-Fatihah antara lain berserah diri, meminta kekuatan, mensyukuri nikmat, mencari hikmah di balik kejadian, dan mengevaluasi diri atas bencana yang menimpanya. Keempat, surat al-Fatihah paling sedikit dibaca 17 kali dalam shalat wajib, sehingga diharapkan memudahkan individu dalam melakukan tugas rumah di luar sesi terapi. Adapun keunikan ART dibandingkan intervensi sejenis (CBT, REBT) adalah:

1. Memperbanyak diskusi untuk menentukan sejumlah pikiran dan keyakinan yang lebih fungsional dalam kandungan ayat-ayat alFatihah, yang kemudian ditawarkan sebagai penjelasan alternatif atau melawan pikiran dan keyakinan disfungsionalnya.

2. Mampu memengaruhi perasaan secara langsung, tanpa melalui proses kognitif (pemaknaan) terlebih dahulu.

3. Tugas rumahnya adalah membaca ayat-ayat al-Fatihah, yaitu berhenti sejenak pada setiap ayatnya, menghayati makna bacaannya (pikiran dan keyakinan yang lebih fungsional yang digali saat sesi terapi), dan menanti jawaban Allah dari apa yang telah diucapkannya itu, seolaholah individu mendengar-Nya.

4. Individu dapat mendapatkan pengalaman spiritual, seperti merasa seolah-olah sedang "berdialog 
langsung" dengan Sang Pencipta.

\section{PENUTUP}

ART merupakan jenis intervensi psikologis yang baru dikembangkan. Meskipun berbagi karakteristik dengan CBT, ART memiliki konsepsi bahwasanya manusia adalah ciptaan Tuhan yang memberikan petunjuk, keringanan, perlindungan, dukungan, dan keberlangsungan hidupnya. ART juga memiliki tata cara yang berbeda dengan CBT, dengan melibatkan ayat-ayat Tuhan (surat al-Fatihah) dalam mengubah pikiran, perasaan, dan perilaku disfungsional individu. Harapan penulis, ART dapat diterapkan, dilakukan penelitiannya, serta dipertimbangkan sebagai intervensi tunggal ataupun intervensi tambahan bagi klien (khususnya muslim) yang mengalami gangguan psikologis.

\section{Daftar Pustaka}

Al-Farmawiy, A. H. (2002). Tafsir Surah Al-Fatihah. Jakarta: Akbar Media Eka Sarana.

Al-Lahim, K.A.K. (2006). Panduan Tadabbur dan Meraih Sukses dengan Al-Qur'an. Jakarta: Fitrah Rabbani.

Ancok, D \& Suroso, F.N. (2008) Psikologi Islami Yogyakarta:Pustaka Pelajar

Arifin, B. (1976). Samudera Al-Fatihah. Surabaya: PT Bina Ilmu.

Atkinson, R.L., Atkinson, R.C., \& Hilgard, E.R. (2003) Introduction to Psychology. Belmont, USA: Wadsworth.

Badri, M.B. (1996). Counseling and Psychotherapy from Islamic Perspective. Journal of the International Institute of Islamic
Thought and Civilization. 1(2),159-191.

Bahreisy, S. \& Bahreisy, S. (1993). Terjemah Singkat Tafsir Ibnu Katsier (jilid I). Surabaya: PT Bina Ilmu.

Beck, J.S. (1995). Cognitive Therapy : Basics and Beyond. New York: The Guilford Press.

Corey, G. (2009). Theory and Practice of Counseling and Psychotheraphy (eighth edition). New York: Thomson Brooks / Cole.

Deacon, B.J., Fawzy, T.I., Lickel, J.J., \& Wolitzky-Taylor, Kate B. (2011). Cognitive Defusion Versus Cognitive Restructuring in the Treatment of Negative Self-Referential Thoughts : An Investigation of Process and Outcome. Journal of Cognitive Psychotherapy : An International Quarterly. 25 (3), 218-232.

Elkadi, A. (1985). Health and Healing In The Qur'an. American Journal of Islamic Social Sciences. 2 (2), 291 296.

Hamdan, A. (2008). Cognitive Restructuring : An Islamic Perspective. Journal of Muslim Mental Health. 3, 99-116.

Leahy, R.L. (2004). Contemporary Cognitive Therapy: Theory, Research, and Practice. The Guilford Press.

Majidi S.A. (2004). Recitation Effect of Holy Quran on Anxiety of Patients Before Undergoing Coronary Artery Angiography. Journal of Guilan University Of Medical Sciences. 13 (49), 61-67.

Najati, M.U. (2010). Psikologi Qurani. 
Jakarta: Nuansa Cendikia.

Padesky, C.A. (1993). Socratic Questioning : Changing Minds or Guiding Discovery. The European Congress of Behavioural and Cognitive Therapies, 1-6.

Purwoko, S.B. (2012). Psikologi Islami: Teori dan Penelitian (edisi kedua). Bandung: Saktiyono WordPress.

Purwoko, S. B. (2012). Pengaruh Restrukturisasi Kognitif melalui alFatihah terhadap Penurunan Derajat Stres pada Penderita Demam Rematik dengan Gejala Korea. Tesis, tidak diterbitkan. Bandung: Universitas Islam Bandung.

Rana, S.A \& North, Adrian C. (2007). The Effect of Rhythmic Quranic Recitation on Depression. Journal of Behavioural Sciences. 17(1-2), 37-53.

Rasyidi, A., Sitanggal, K. Anshori U., Aly, Hery N \& Abubakar, Bahrun. (1992). Terjemah Tafsir Al-Maragi (jilid 1). Semarang: CV Toha Putra.

Razali SM, Hasanah CI, Aminah K \& Subramaniam M. (1998). ReligiousSociocultural Psychotherapy in Patients With Anxiety and Depression. Aust NZJPsychiatry. 32 (6), 867-72.

Richards, P.S. \& Bergin, A.E. (2006). $A$ Spiritual Strategy for Counseling and Psychotherapy (2 ${ }^{\text {nd }}$ edition). Washington DC: American PsychologicalAssociation.

Rosenberg, R. S \& Kosslyn, S.M. (2011). Abnormal Psychology. Belmont, USA: Wadsworth Publishers.
Scott, J., Williams, J.M.G., \& Beck, A. T. (1989). Cognitive Therapy in Clinical Practice : An Illustrative Casebook. New York: Routledge.

Shihab, M.Q. (2004). Tafsir Al-Mishbah: Pesan, Kesan dan Keserasian alQur'an (volume 1). Jakarta: Penerbit Lentera Hati.

Waller, R., Trepka, C., Collerton, D., \& Hawkins, J. (2010). Addressing Spirituality in CBT. The Cognitive Behaviour Therapist. 3, 95-106.

York, C.M. (2011). The Effects of Ruqya on A Non-Muslim : A Multiple Case Study Exploration. Dissertation. Palo Alto California.: Institute of Transpersonal Psychology.

\section{Internet}

http://www.alquran-digital.com, diakses 6 Desember 2011

http://oxforddictionaries.com/definition/e nglish/reflection?q=reflection, diakses 8 Maret 2013

http://dictionary.reference.com/browse/re flection, diakses 8 Maret 2013

http://www.thefreedictionary.com/reflecti on, diakses 8 Maret 2013

http://quran.com/38, diakses 8 Maret 2013

http://corpus.quran.com/translation.jsp?c hapter $=38 \&$ verse $=29$, diakses 8 Maret 2013 